OPEN ACCESS

Edited by:

Peixin Dong,

Hokkaido University, Japan

Reviewed by:

Daozhi Xu,

Shenyang Medical College, China

Mohammad Taheri,

Jena University Hospital, Germany

*Correspondence:

Wenzhi Guo

fccguowz@zzu.edu.cn

Yuting $\mathrm{He}$

fccheyt1@zzu.edu.cn

${ }^{t}$ These authors have contributed equally to this work

Specialty section:

This article was submitted to Epigenomics and Epigenetics, a section of the journal Frontiers in Cell and Developmental Biology

Received: 03 August 2021 Accepted: 22 September 2021

Published: 07 October 2021

Citation:

YuX, Zheng $Q$, Zhang $Q$, Zhang S, He Y and Guo W (2021) MCM3AP-AS1: An Indispensable

Cancer-Related LncRNA. Front. Cell Dev. Biol. 9:752718. doi: 10.3389/fcell.2021.752718

\section{MCM3AP-AS1: An Indispensable Cancer-Related LncRNA}

\author{
Xiao Yu ${ }^{1,2,3,4 t}$, Qingyuan Zheng ${ }^{1,2,3,4 t}$, Qiyao Zhang ${ }^{1,2,3,4 t}$, Shuijun Zhang ${ }^{1,2,3,4}$, \\ Yuting $\mathrm{He}^{1,2,3,4 *}$ and Wenzhi Guo ${ }^{1,2,3,4 *}$
}

'Department of Hepatobiliary and Pancreatic Surgery, The First Affiliated Hospital of Zhengzhou University, Zhengzhou, China, ${ }^{2}$ Key Laboratory of Hepatobiliary and Pancreatic Surgery and Digestive Organ Transplantation of Henan Province, The First Affiliated Hospital of Zhengzhou University, Zhengzhou, China, ${ }^{3}$ Open and Key Laboratory of Hepatobiliary \& Pancreatic Surgery and Digestive Organ Transplantation at Henan Universities, Zhengzhou, China, ${ }^{4}$ Henan Key Laboratory of Digestive Organ Transplantation, Zhengzhou, China

Long non-coding RNAs (IncRNAs) are a class of RNA molecules with transcripts longer than 200 nucleotides that have no protein-coding ability. MCM3AP-AS1, a novel IncRNA, is aberrantly expressed in human cancers. It is significantly associated with many clinical characteristics, such as tumor size, tumor-node-metastasis (TNM) stage, and pathological grade. Additionally, it considerably promotes or suppresses tumor progression by controlling the biological functions of cells. MCM3AP-AS1 is a promising biomarker for cancer diagnosis, prognosis evaluation, and treatment. In this review, we briefly summarized the published studies on the expression, biological function, and regulatory mechanisms of MCM3AP-AS1. We also discussed the clinical applications of MCM3AP-AS1 as a biomarker.

\section{Keywords: long non-coding RNA, MCM3AP-AS1, biological function, regulatory mechanism, biomarker}

\section{INTRODUCTION}

Cancer is a fatal disease that is often caused by somatic mutations (Kennedy et al., 2019; Andrei et al., 2020; Costa et al., 2020). Genomic alterations can lead to a series of malignant features, including cell migration, invasion, and metastasis. Conventional cancer therapies, including surgery, radiotherapy, and chemotherapy, have limitations (Liang et al., 2021). Molecular targeted therapy, a new therapeutic approach, overcomes these limitations and has advantages in cancer treatment (Ethier et al., 2021).

Long non-coding RNAs (lncRNAs) are a class of RNA molecules with transcript lengths longer than 200 nucleotides that have no protein-coding ability (Thum, 2014; Lorenzen and Thum, 2016; Liu et al., 2017; Xu et al., 2020; Jin et al., 2021). The function of lncRNAs is related to their special subcellular localization. The lncRNAs located in the nucleus participate in gene regulation at the epigenetic and transcription levels. Moreover, lncRNAs in the cytoplasm are involved in interactions with proteins in the cytoplasm and the regulation of the metabolism of mRNAs, such as endogenous competitive RNAs (ceRNAs), which interact with microRNAs. Increasing evidence indicates that lncRNAs are important modulators of different biological functions (Zehendner et al., 2020). The overexpression of lncRNA OTUD6B-AS1 inhibits cell proliferation, migration, and invasion in clear cell renal cell carcinoma (Wang et al., 2019a). Elevated levels of lncRNA H19 decreased sensitivity to tamoxifen in breast cancer (Wang et al., 2019b). Moreover, lncRNAs have been reported to function via multiple signaling pathways in cancer progression. LNRRIL6 promotes cancer progression by activating the IL-6/STAT3 pathway 
in colorectal cancer (CRC) (Wang et al., 2019c). Long noncoding RNA EPB41L4A-AS2 inhibits cell proliferation and migration by downregulating miR-301a-5p expression and upregulating FOXL1 expression in hepatocellular carcinoma (HCC) (Wang et al., 2019f).

MCM3AP-AS1 is located in 46,228,977-46,259,390 of chromosome 21, and the subcellular localization of MCM3APAS1 is chromatin and nucleoplasm (Figure 1A). MCM3AP-AS1 was found to be dysregulated in a variety of cancers, including breast cancer, $\mathrm{CRC}$, gastric cancer, $\mathrm{HCC}$, and prostate cancer (PCa). MCM3AP-AS1 has great potential for use in cancer diagnosis, prognosis evaluation, and treatment. In this review, we first summarized the expression profile of MCM3AP-AS1 and the cellular processes in which MCM3AP-AS1 is involved. Then, we clarified the mechanism of MCM3AP-AS1 in two parts: in vitro cell experiments and in vivo experiments. The former part enabled superficial function verification, while the latter enabled further confirmation of the potential regulatory mechanism of MCM3AP-AS1. Briefly, we outline the role of lncRNA MCM3AP-AS1 in tumorigenesis by integrating recent research findings.

\section{EVIDENCE ACQUISITION}

We carried out exhaustive research employing PubMed and the Web of Science database to seek articles up to August 2021 using the keywords MCM3AP-AS1, MCM3AP-AS, MCM3APAS, tumor, cancer, and carcinoma. We assessed all results according to the titles and abstracts and selected articles related to our theme. All unrelated articles, letters, meeting proceedings, correction articles, and retracted articles were excluded. After this, the full text of any selected article was reviewed independently by two authors. Figure 1B shows a flow diagram of the study selection process.

\section{EXPRESSION AND BIOLOGICAL FUNCTIONS OF MCM3AP-AS1 IN HUMAN CANCER}

The expression levels of MCM3AP-AS1 are significantly dysregulated in human cancers (Table 1). MCM3AP-AS1 plays a vital role in the occurrence and development of various cancers. Its expression is significantly associated with several clinical characteristics. Moreover, in vitro assays have shown that it markedly promotes or suppresses tumor progression by controlling cell biological functions. In this section, we discussed the emerging roles of MCM3AP-AS1 in different cancers (Table 2).

\section{Breast Cancer}

Breast cancer is one of the most common types of malignancy in women worldwide (Liang et al., 2020; Carreira et al., 2021; Han et al., 2021). The levels of lncRNA MCM3APAS1 are significantly upregulated in breast cancer tissues and cell lines (Chen et al., 2020; Riahi et al., 2021). The level of
MCM3AP-AS1 was positively associated with estrogen receptor (ER) and progesterone receptor (PR) expression, whereas no significant differences were observed between MCM3APAS1 and HER2 expression profiles in breast cancer patients. Functionally, MCM3AP-AS1 affected cell biological functions to control breast cancer progression by regulating specific pathways. MCM3AP-AS1 knockout inhibited the proliferation, invasion, and migration of breast cancer cell lines. These findings may facilitate the development of novel therapeutics for breast cancer.

\section{Colorectal Cancer}

Colorectal cancer (CRC) is one of the most prevalent cancers and a leading cause of cancer-related death worldwide (Oki et al., 2016; Wang et al., 2019d; Yarla et al., 2019; Zhao et al., 2021). Some studies have revealed that MCM3AP-AS1 expression is markedly upregulated in CRC tissues compared to corresponding normal tissues (Ma et al., 2020; Zhou et al., 2021). In terms of prognosis, MCM3AP-AS1 levels are negatively associated with overall survival (OS). Functionally, elevated MCM3APAS1 expression promotes cell proliferation, colony formation, migration, and invasion and arrests the cell cycle at the G1 phase in CRC cell lines (Ma et al., 2020; Zhou et al., 2021) (Figure 2). In contrast, Dai et al. found that MCM3AP-AS1 expression was decreased in CRC tissues (Dai et al., 2021). The expression of MCM3AP-AS1 was positively correlated with OS in CRC patients. Moreover, the levels of MCM3AP-AS1 were negatively associated with tumor-node-metastasis (TNM) stage, tumor size, and carcinoembryonic antigen (CEA) levels in CRC. Functionally, MCM3AP-AS1 significantly reduced the proliferation and migration of CRC cells (Figure 2). The results were validated by siRNA knockdown experiments. However, MCM3AP-AS1 expression needs to be further studied in CRC. Further evidence-based basic and clinical studies are needed to increase the evidence base.

\section{Gastric Cancer}

Gastric cancer is the fifth most common malignancy and the second leading cause of cancer-related mortality worldwide (Liu et al., 2016; Seidlitz et al., 2019; Kang et al., 2020; Harada et al., 2021; Li et al., 2021). Cisplatin (CDDP) is a well-known chemotherapeutic agent used to treat gastric cancer (Germann et al., 2002; Ivanova et al., 2013; Huang et al., 2019). Cisplatin resistance is the main reason for the poor therapeutic effects in gastric cancer (Wang et al., 2018; Zhang Q. et al., 2020). The expression levels of MCM3AP-AS1 were evidently upregulated in MGc-803, SGC-7901, NCI-N87 (NCI-N87/CDDP), and AGS cells (AGS/CDDP) (Wang et al., 2020; Sun et al., 2021). In vitro evidence suggested that the levels of MCM3AP-AS1 are positively associated with the half-maximal inhibitory concentration $\left(\mathrm{IC}_{50}\right)$ of CDDP in gastric cancer. MCM3AP-AS1 was also found to facilitate cell proliferation, migration, and invasion and decrease CDDP sensitivity in gastric cancer cell lines (Sun et al., 2021).

\section{Liver Cancer}

Hepatocellular carcinoma (HCC) is a common primary malignancy of the liver and typically occurs in patients with underlying chronic liver disease (Degasperi et al., 2020; 


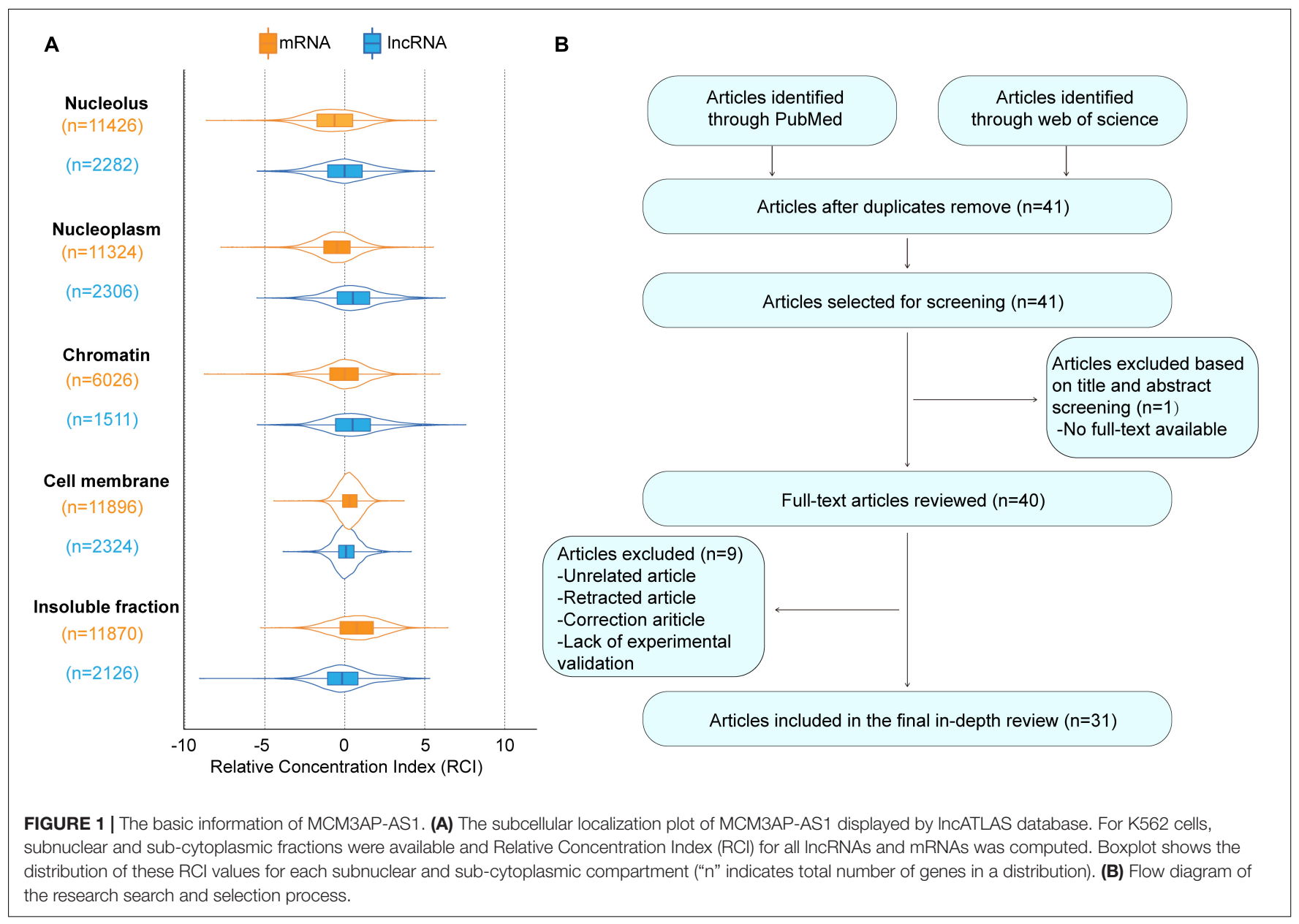

Goh et al., 2020; Yip et al., 2020; Zhou et al., 2020; Xia et al., 2021). MCM3AP-AS1 expression is upregulated in HCC tissues and cell lines (Wang et al., 2019e). The levels of MCM3AP-AS1 are positively associated with tumor size, stage, and grade in HCC patients. Increased MCM3AP-AS1 expression was associated with a worse prognosis in HCC (Wang et al., 2019e; Zhang et al., 2019). In vitro cell experiments suggested that silencing MCM3AP-AS1 inhibited the formation of human lymphatic endothelial cells in HCC. Moreover, MCM3AP-AS1 significantly promotes the proliferation, colony formation, cell cycle progression, and metastasis of HCC cells (Wang et al., 2019e; Zhang et al., 2019).

\section{Oral Squamous Cell Carcinoma}

Oral squamous cell carcinoma (OSCC), a head and neck cancer, seriously affects the quality of life of affected patients, both psychologically and physically ( $\mathrm{Ng}$ et al., 2017; Bray et al., 2018; Almangush et al., 2020). Hou et al. revealed that MCM3AP-AS1 expression was elevated in both OSCC cells and tissues and that a high expression level of MCM3APAS1 was correlated with a poor prognosis in OSCC patients. Moreover, overexpression of MCM3AP-AS1 could enhance the proliferation, migration, and invasion of OSCC cells. Inhibiting MCM3AP-AS1 had the opposite effect on the above cell events
(Hou et al., 2020). Li et al. found similar phenomena in OSCC cells and found different molecular mechanisms than $\mathrm{Hou}$, which would be elaborated in a later section (Li and Jiang, 2020). Therefore, we have adequate evidence to indicate that MCM3AP-AS1 has the potential to act as a biomarker for OSCC patients.

\section{Prostate Cancer}

Prostate cancer $(\mathrm{PCa})$ is the most commonly diagnosed cancer and the second leading cause of cancer-related death in Americans (Amarasekera et al., 2019; Berger et al., 2019; Ge et al., 2020). The expression levels of MCM3AP-AS1 were markedly increased in PCa tissues and cell lines (Jia et al., 2020; Li et al., 2020a; Wu et al., 2020). MCM3AP-AS1 levels were negatively correlated with OS in PCa patients (Jia et al., 2020; Chen et al., 2021).

A negative association has also been reported between MCM3AP-AS1 and disease-free survival in PCa (Wu et al., 2020). MCM3AP-AS1 expression correlates with the Gleason score, pathological stage, and androgen receptor expression in PCa (Li et al., 2020a). MCM3AP-AS1 knockdown inhibited cell proliferation, migration, and invasion and promoted the apoptosis of PCa cell lines (Jia et al., 2020; Li et al., 2020a; $\mathrm{Wu}$ et al., 2020). In addition, MCM3AP-AS1 expression 
TABLE 1 | Expression and associated clinical features of the IncRNA MCM3AP-AS1 in cancer.

\begin{tabular}{|c|c|c|c|}
\hline Type & Expression & Feature & References \\
\hline Breast cancer & upregulated & $\begin{array}{l}\text { tumor estrogen receptor expression, and tumor progesterone } \\
\text { receptor expression }\end{array}$ & Riahi et al., 2021 \\
\hline Burkitt Lymphoma & upregulated & tumor size, tumor stage, and poor prognosis & Guo et al., 2020 \\
\hline Cervical squamous cell carcinoma & downregulated & poor survival & Lan et al., 2020 \\
\hline Clear cell renal cell carcinoma & upregulated & / & Wang et al., 2019a \\
\hline Colorectal cancer & upregulated & poor survival & Ma et al., 2020 \\
\hline Colorectal cancer & downregulated & poor prognosis, higher TNM stage, tumor size, and CEA level & Dai et al., 2021 \\
\hline Colorectal cancer & upregulated & poor survival & Zhou et al., 2021 \\
\hline Endometrioid carcinoma & upregulated & / & Yu J. et al., 2021 \\
\hline Hepatocellular carcinoma & upregulated & $\begin{array}{l}\text { large tumor size, high tumor grade, advanced tumor stage, and } \\
\text { poor prognosis }\end{array}$ & Wang et al., 2019e \\
\hline Hepatocellular carcinoma & / & overall survival & Zhang et al., 2019 \\
\hline Nasopharyngeal carcinoma & upregulated & poor survival & Sun et al., 2020 \\
\hline Lung cancer & upregulated & / & Li et al., 2020b \\
\hline Small cell lung cancer & upregulated & survival rate & Luo et al., 2021 \\
\hline Non-small cell lung cancer & upregulated & / & Shen et al., 2021 \\
\hline Oral squamous cell carcinoma & upregulated & poor prognosis & Hou et al., 2020 \\
\hline Oral squamous cell carcinoma & upregulated & / & Li and Jiang, 2020 \\
\hline Pancreatic cancer & upregulated & survival rates & Yang et al., 2019 \\
\hline Prostate cancer & upregulated & overall survival & Jia et al., 2020 \\
\hline Prostate cancer & upregulated & pathological stage, Gleason score, and AR expression & Li et al., 2020a \\
\hline Prostate cancer & / & overall survival & Chen et al., 2021 \\
\hline Prostate cancer & upregulated & disease-free survival & Wu et al., 2020 \\
\hline
\end{tabular}

was significantly associated with bone metastases in $\mathrm{PCa}$ (Chen et al., 2021).

\section{Lung Cancer}

Lung cancer (LC) continues to be one of the most frequent cancers worldwide. The number of patients and deaths related to LC has continued to increase in recent years (Schwartz and Cote, 2016; Jones and Baldwin, 2018; Bade and Dela Cruz, 2020). MCM3AP-AS1 was elevated in small cell lung cancer (SCLC), and a high expression level of MCM3AP-AS1 was accompanied by a low survival rate. MCM3AP-AS1 overexpression could facilitate the migration and invasion of SCLC cells (Luo et al., 2021). In non-small-cell lung cancer (NSCLC), MCM3AP-AS1 was also obviously upregulated. MCM3AP-AS1 also could promote the proliferation, invasion, and migration of NSCLC cells. Li et al. generally found that MCM3AP-AS1 could accelerate angiogenesis, in addition to cell proliferation and migration, in LC. In conclusion, MCM3AP-AS1 had the potential to act as a biomarker in LC (Li et al., 2020b).

\section{Reproductive System Cancers}

For females, the incidence and motility of reproductive system cancers are the highest among cancers worldwide, indicating that they seriously threaten women's health (Torre et al., 2017; Hernandez-Silva et al., 2020). Interestingly, MCM3APAS1 participates in the progression of most reproductive system cancers, including cervical cancer and endometrial cancer. For endometrioid carcinoma (EC), MCM3AP-AS1 expression was upregulated in cancer tissues compared with adjacent normal tissues. Overexpression of MCM3AP-AS1 increased the migration and invasion rate of EC cells. Both migration and invasion were inhibited when MCM3AP-AS1 was knocked down (Yu J. et al., 2021). However, Lan et al. demonstrated that MCM3AP-AS1 expression was reduced in cervical squamous cell carcinoma (CSCC) and that MCM3AP-AS1 overexpression significantly inhibit the proliferation of CSCC cells (Lan et al., 2020). These results suggest that MCM3AP-AS1 plays dual roles in reproductive tumors, and the underlying mechanism is probably worth studying.

\section{Other Cancers}

MCM3AP-AS1 was also found to be upregulated in Burkitt lymphoma, glioblastoma, LC, nasopharyngeal carcinoma, clear cell renal cell carcinoma, pancreatic cancer, and papillary thyroid cancer tissues compared to the corresponding normal tissues (Yang et al., 2017, 2019; Liang et al., 2019; Guo et al., 2020; Li et al., 2020b; Qiu et al., 2020; Sun et al., 2020). The MCM3AP-AS1 expression profile was positively associated with tumor size and stage in Burkitt lymphoma. Higher levels of MCM3AP-AS1 indicate a worse prognosis in Burkitt lymphoma, nasopharyngeal carcinoma, and pancreatic cancer. Further in vitro experiments confirmed that MCM3AP-AS1 expression was upregulated in pancreatic cancer cell lines (PANC-1, BxPC3, MIA PaCa-2, Capan-2, and AsPC-1). MCM3AP-AS1 inhibited cell proliferation and migration in LC, pancreatic cancer, and papillary thyroid cancer. It also promoted tumor angiogenesis in glioblastoma and LC and increased cell viability in Burkitt lymphoma and glioblastoma. 
TABLE 2 | The biological functions and molecular mechanisms of MCM3AP-AS1.

\begin{tabular}{|c|c|c|c|c|}
\hline Type & Expression & Function & Related genes & References \\
\hline Breast cancer & upregulated & cell proliferation, migration, and invasion & miR-28-5p, and CENPF & Chen et al., 2020 \\
\hline Breast cancer & upregulated & cell proliferation & $\operatorname{miR}-708-5 p$ & Riahi et al., 2021 \\
\hline Burkitt lymphoma & upregulated & cell viability, apoptosis, and chemoresistance & miR-15a, and EIF4E & Guo et al., 2020 \\
\hline $\begin{array}{l}\text { Cervical squamous cell } \\
\text { carcinoma }\end{array}$ & downregulated & cell proliferation & $\operatorname{miR}-93$ & Lan et al., 2020 \\
\hline Colorectal cancer & upregulated & cell cycle & miR-545, and CDK4 & Ma et al., 2020 \\
\hline $\begin{array}{l}\text { Clear cell renal cell } \\
\text { carcinoma }\end{array}$ & upregulated & proliferation, inflammation, Pro-angiogenesis & E2F1, DPP4 & Wang et al., 2019a \\
\hline Colorectal cancer & downregulated & cell proliferation, and migration & miR-19a-3p, and FOXF2 & Dai et al., 2021 \\
\hline Colorectal cancer & upregulated & $\begin{array}{l}\text { cell proliferation, colony formation, migratory, and } \\
\text { invasive ability }\end{array}$ & miR-193a-5p, and SENP1 & Zhou et al., 2021 \\
\hline Colorectal cancer & / & / & miR-599, and ARPP19 & Yu Y. et al., 2021 \\
\hline $\begin{array}{l}\text { Endometrioid } \\
\text { carcinoma }\end{array}$ & upregulated & invasion, and migration & miR-708-5p & Yu J. et al., 2021 \\
\hline Gastric cancer & $\begin{array}{l}\text { upregulated (CDDP } \\
\text { resistance) }\end{array}$ & CDDP resistance & miR-138, and FOXC1 & Sun et al., 2021 \\
\hline Gastric cancer & upregulated & cell proliferation, and apoptosis & miR-708-5p & H Wang et al., 2020 \\
\hline Glioblastoma & upregulated & $\begin{array}{l}\text { cell viability, migration, tube formation of GECs, and } \\
\text { angiogenesis }\end{array}$ & miR-211, KLF5, and AGGF1 & Yang et al., 2017 \\
\hline $\begin{array}{l}\text { Hepatocellular } \\
\text { carcinoma }\end{array}$ & upregulated & $\begin{array}{l}\text { cell proliferation, colony formation, cell cycle } \\
\text { progression, and induced apoptosis }\end{array}$ & $\begin{array}{l}\text { miR-194-5p, FOXA1, and } \\
\text { FOXA1 restoration }\end{array}$ & Wang et al., 2019e \\
\hline $\begin{array}{l}\text { Hepatocellular } \\
\text { carcinoma }\end{array}$ & / & invasion, and HDLECs & miR-455, and EGFR & Zhang et al., 2019 \\
\hline Lung cancer & upregulated & cell proliferation, migration, and angiogenesis & YY1, miR-340-5p, and KPNA4 & Li et al., 2020b \\
\hline Small cell lung cancer & upregulated & invasion, and migration & miR-148a, and ROCK1 & Luo et al., 2021 \\
\hline $\begin{array}{l}\text { Non-small cell lung } \\
\text { cancer }\end{array}$ & upregulated & proliferation, migration and invasion & miR-195-5p, and E2F & Shen et al., 2021 \\
\hline $\begin{array}{l}\text { Nasopharyngeal } \\
\text { carcinoma }\end{array}$ & upregulated & cell proliferation, and apoptosis & miR-34a & Sun et al., 2020 \\
\hline $\begin{array}{l}\text { Oral squamous cell } \\
\text { carcinoma }\end{array}$ & upregulated & proliferation, migration and invasion & miR-363-5p & Hou et al., 2020 \\
\hline $\begin{array}{l}\text { Oral squamous cell } \\
\text { carcinoma }\end{array}$ & upregulated & proliferation, migration and invasion & miR-204-5p, and FOXC1 & Li and Jiang, 2020 \\
\hline Pancreatic cancer & upregulated & proliferation, migration, and invasion & miR-138-5p, and FOXK1 & Yang et al., 2019 \\
\hline Papillary thyroid cancer & upregulated & proliferation, migration, and invasion & miR-211-5p, and SPARC & Liang et al., 2019 \\
\hline Prostate cancer & upregulated & proliferation, and invasion & $\begin{array}{l}\text { miR-543-3p, SLC39A10, and } \\
\text { PTEN }\end{array}$ & Jia et al., 2020 \\
\hline Prostate cancer & upregulated & proliferation, invasion, migration, and apoptosis & $\begin{array}{l}\text { DNMT1, DNMT3, NPY1R, and } \\
\text { MAPK }\end{array}$ & Li et al., 2020a \\
\hline Prostate cancer & / & bone metastasis & / & Chen et al., 2021 \\
\hline Prostate cancer & upregulated & proliferative ability, and apoptosis & $\begin{array}{l}\text { miR-876-5p, WNT5A, and } \\
\text { WNT5A }\end{array}$ & Wu et al., 2020 \\
\hline
\end{tabular}

In contrast to the above findings, MCM3AP-AS1 expression is markedly downregulated in CSCC tissue samples and predicts a poor outcome. Overexpression of MCM3AP-AS1 reduces CSCC cell proliferation, and MCM3AP-AS1 acts as a tumor suppressor during CSCC development and progression.

In conclusion, MCM3AP-AS1 expression was markedly elevated in breast cancer (Chen et al., 2020; Riahi et al., 2021), Burkitt lymphoma (Guo et al., 2020), gastric cancer (Wang et al., 2020; Sun et al., 2021), glioblastoma (Yang et al., 2017), HCC (Wang et al., 2019e), LC (Li et al., 2020b), nasopharyngeal carcinoma (Sun et al., 2020), pancreatic cancer (Yang et al., 2019), papillary thyroid cancer (Liang et al., 2019), and PCa (Li et al., 2020a; Wu et al., 2020). However, MCM3AP-AS1 expression was downregulated in CSCC patients (Lan et al., 2020) (Table 1). Collectively, MCM3AP-AS1 has the potential to act as a prognostic biomarker for many cancers.

\section{REGULATORY MOLECULAR MECHANISMS OF MCM3AP-AS1 IN HUMAN CANCER}

From the aforementioned studies, we can conclude that MCM3AP-AS1 plays an important role in the regulation of various biological functions, such as cell growth, motility, cell cycle, drug resistance, and angiogenesis. In this section, 


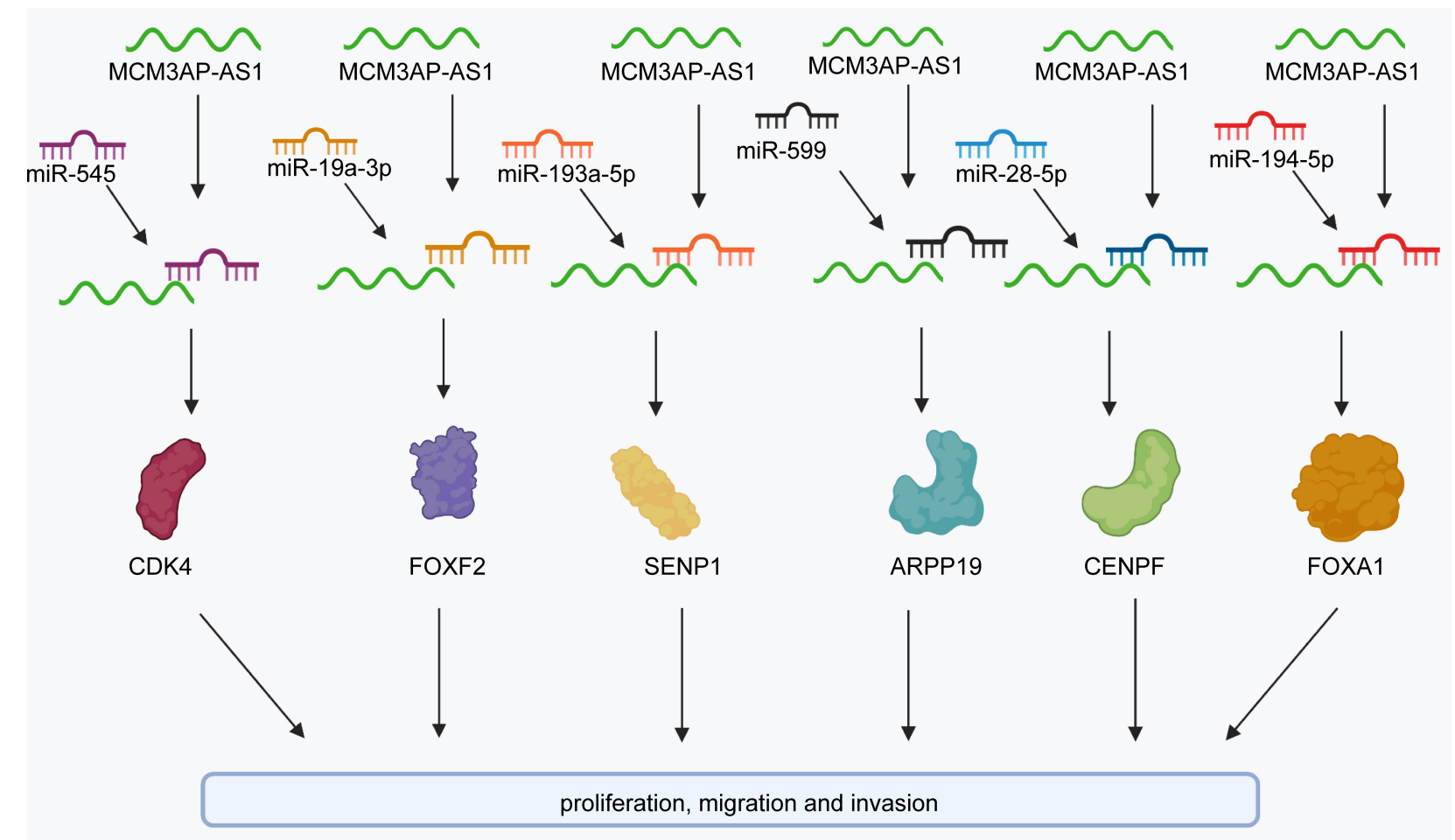

FIGURE 2 | The regulatory molecular mechanisms of the IncRNA MCM3AP-AS1 in CRC, breast cancer, and liver cancer. MCM3AP-AS1 facilitates the expression of SENP1 to attenuate cell proliferation and colony formation by sponging miR-193a-5p in CRC. MCM3AP-AS1 promotes the expression of FOXF2 to inhibit cell proliferation by sponging miR-19a-3p in CRC. It also promotes the cell cycle by activating the miR-545/CDK4 pathway. MCM3AP-AS1 inhibits ARPP19 levels by sponging miR-599 in colorectal cancer.

we summarized the regulatory molecular mechanisms of MCM3AP-AS1 in cancer, both in vivo and in vitro.

\section{In vitro Cell Experiment}

\section{Cell Growth}

MCM3AP-AS1 facilitates cell proliferation by reducing miR-708-5p levels in breast cancer cells (Riahi et al., 2021). MCM3AP-AS1 facilitates the expression of SENP1 to attenuate cell proliferation and colony formation by sponging miR-193a-5p in CRC cells (Zhou et al., 2021). It also inhibited gastric cancer cell proliferation and promoted apoptosis by downregulating miR-708-5p levels (Wang et al., 2020). In HCC, MCM3AP-AS1 regulates cellular processes, such as cell proliferation, cell cycle progression, and cell apoptosis by activating the miR194-5p/FOXA1 pathway (Wang et al., 2019e). MCM3AP-AS1 enhances the proliferation of $\mathrm{PCa}$ cells by the miR-5433p/SLC39A10/PTEN (Figure 3) and miR-876-5p/WNT5A pathways in PCa (Jia et al., 2020; Li et al., 2020a). Additionally, it activates the MAPK pathway to induce cell proliferation by promoting methylation of the NPY1R promoter in $\mathrm{PCa}(\mathrm{Wu}$ et al., 2020). Silencing of MCM3AP-AS1 suppresses KPNA4 expression to impair cell proliferation by acting as a sponge of miR-340-5p in LC (Li et al., 2020b). MCM3AP-AS1 does not affect the levels of miR-34a, whereas elevated miR-34a expression suppresses cell proliferation by downregulating MCM3AP-AS1 expression in nasopharyngeal carcinoma (Sun et al., 2020). Silencing MCM3AP-AS1 expression inhibits cell proliferation and colony formation by regulating the miR-138-5p/FOXK1 axis in pancreatic cancer (Yang et al., 2019) and plays the same role by controlling the miR-211-5p/SPARC pathway in papillary thyroid cancer (Liang et al., 2019). In contrast, MCM3AP-AS1 markedly downregulates the expression of miR-93 and inhibited cell proliferation in CSCC (Lan et al., 2020). Some researchers have found that MCM3AP-AS1 promotes the expression of FOXF2 to enhance cell proliferation by sponging miR-19a-3p in CRC (Dai et al., 2021).

\section{Cell Motility}

Cell motility is a physiological process that is required for embryonic development, wound healing, immune surveillance, and cancer metastasis (Tojkander et al., 2015; Swaminathan et al., 2016; Cummins et al., 2018). MCM3AP-AS1 functions as a sponge of miR-193a-5p to upregulate SENP1 expression and facilitate cell migration and invasion in CRC (Zhou et al., 2021). Overexpression of MCM3AP-AS1 enhances cell migration and invasion by regulating DNMT1/DNMT3 (A/B) methylation-mediated overexpression of NPY1R and the miR543-3p/SLC39A10/PTEN pathway in PCa (Jia et al., 2020; Li et al., 2020a). MCM3AP-AS1 expression is mediated by YY1 and promotes the upregulation of KPNA4, which facilitated the migration of LC cells by sponging miR-340-5p (Li et al., 2020b). 


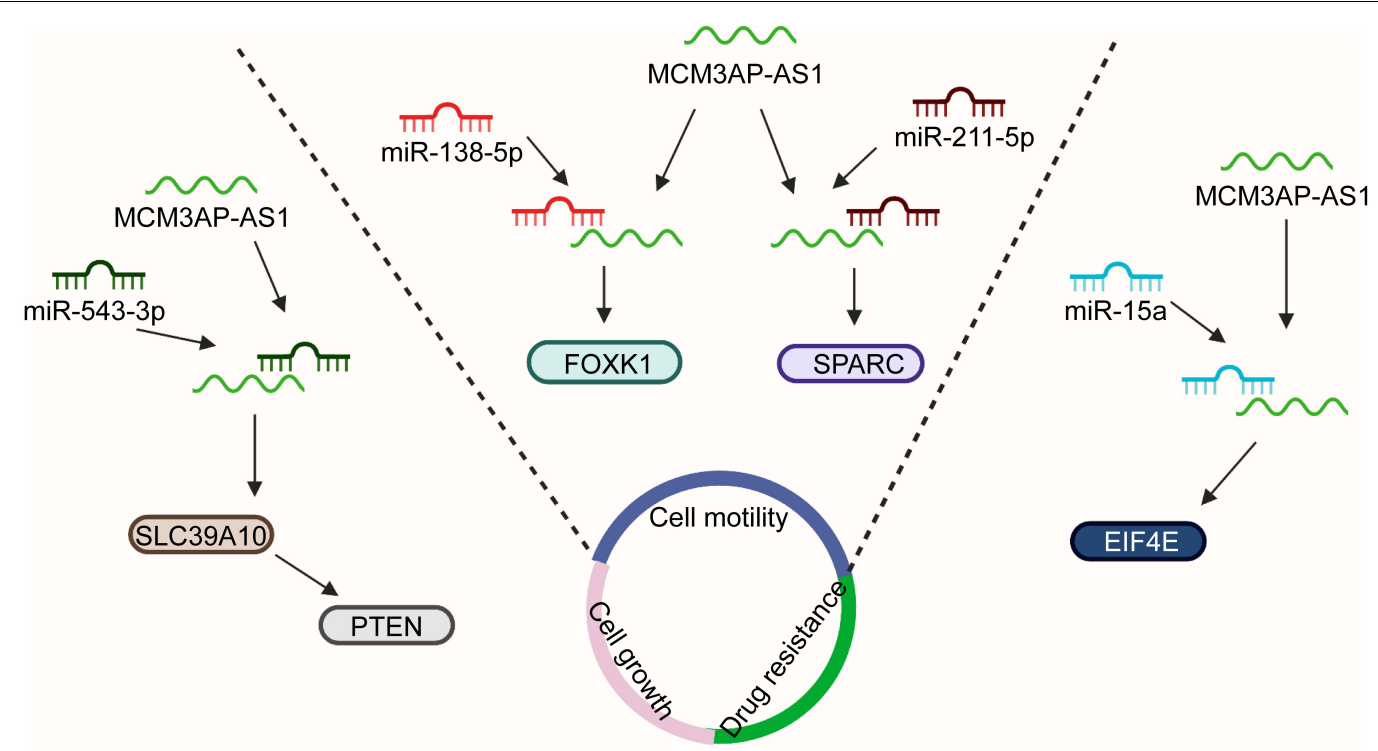

FIGURE 3 | MCM3AP-AS1 functions by interacting with specific molecular pathways. MCM3AP-AS1 enhances cell proliferation via the miR-543-3p/SLC39A10/PTEN axis in PCa. MCM3AP-AS1 reduces the levels of miR-138-5p and increases the expression of FOXK1 to promote cell migration in pancreatic cancer. Cell invasion is enhanced by the activation of the miR-211-5p/SPARC pathway in papillary thyroid cancer. MCM3AP-AS1 regulates the sensitivity of lymphoma cells to doxorubicin by regulating the miR-15a/EIF4E pathway.

LncRNA MCM3AP-AS1 reduces the levels of miR-138-5p and increased the expression of FOXK1, promoting cell migration in pancreatic cancer (Yang et al., 2019) (Figure 3). Cell proliferation and invasion are enhanced by the activation of the miR-211-5p/SPARC pathway in papillary thyroid cancer (Liang et al., 2019).

\section{Angiogenesis and Drug Resistance}

Angiogenesis, the formation of new blood vessels from existing vessels, plays a critical role in physiological and pathological conditions (Ramjiawan et al., 2017; Li et al., 2019). Aberrant angiogenesis can support the metabolism of tumors and contribute to tumor progression (Cebulla et al., 2014; Wu et al., 2014; Mao et al., 2015). The lncRNA MCM3APAS1 accelerated tumor angiogenesis by targeting the miR211/KLF5/AGGF1 pathway in glioblastoma (Yang et al., 2017). The elevated expression of MCM3AP-AS1 facilitates angiogenesis by regulating the miR-340-5p/KPNA4 axis in LC (Li et al., 2020b). Resistance to chemotherapy is the main cause of chemotherapy failure in cancers ( $\mathrm{Si}$ et al., 2019; Gao et al., 2020; Jena and Mandal, 2021). In vitro evidence suggests that increased MCM3AP-AS1 controls the sensitivity of lymphoma cells to doxorubicin by regulating the miR-15a/EIF4E pathway (Guo et al., 2020) (Figure 3). MCM3AP-AS1 reduces gastric cancer cell sensitivity to cisplatin by regulating the miR-138/FOXC1 pathway (Sun et al., 2021). The results may provide novel ideas for targeted therapy of lymphoma and gastric cancer.

\section{Experiments in vivo}

The results of the in vitro experiments were further confirmed by experiments using animal models in vivo. In a nude mouse model of CRC, MCM3AP-AS1 expression was positively associated with tumor growth, tumor weight, and the number of lung metastatic tumor nodules (Zhou et al., 2021). MCM3AP-AS1 promotes tumor growth by activating the miR-28-5p/CENPF pathway in breast cancer in vivo (Chen et al., 2020). Furthermore, MCM3APAS1 enhanced the levels of FOXA1 to suppress tumorigenesis by sponging miR-194-5p in an HCC xenograft model (Wang et al., 2019e). Moreover, MCM3AP-AS1 silencing decreased the volume of PCa and inhibited the expression of SLC39A10 in BALB/c mice (Jia et al., 2020). MCM3AP-AS1 also contributed to $\mathrm{PCa}$ progression via regulation of the MAPK/NPY1R axis in vivo (Li et al., 2020a). Animal experiments have demonstrated that downregulation of MCM3AP-AS1 contributes to the expression of miR-15a and PARP, whereas it inhibits the expression of Mcl-1 and EIF4E in lymphoma (Guo et al., 2020). MCM3AP-AS1 significantly promotes tumor growth by activating the miR-211-5p/SPARC pathway in papillary thyroid cancer (Liang et al., 2019).

In vivo and in vitro, MCM3AP-AS1 has various biological functions, including cell proliferation, colony formation, migration, invasion, and chemoresistance. Interestingly, the mechanisms related to MCM3AP-AS1 are all similar and involve the ceRNA network. For researchers in related fields, this idea is worthy of reference.

\section{MCM3AP-AS1 AS A BIOMARKER AND TREATMENT TARGET IN CANCER}

Cancer prognosis monitoring is critical for reducing cancer-related deaths. Dysregulated expression patterns of MCM3AP-AS1 have great value for the diagnosis and prognosis of cancer. The levels of lncRNA MCM3AP-AS1 are negatively 


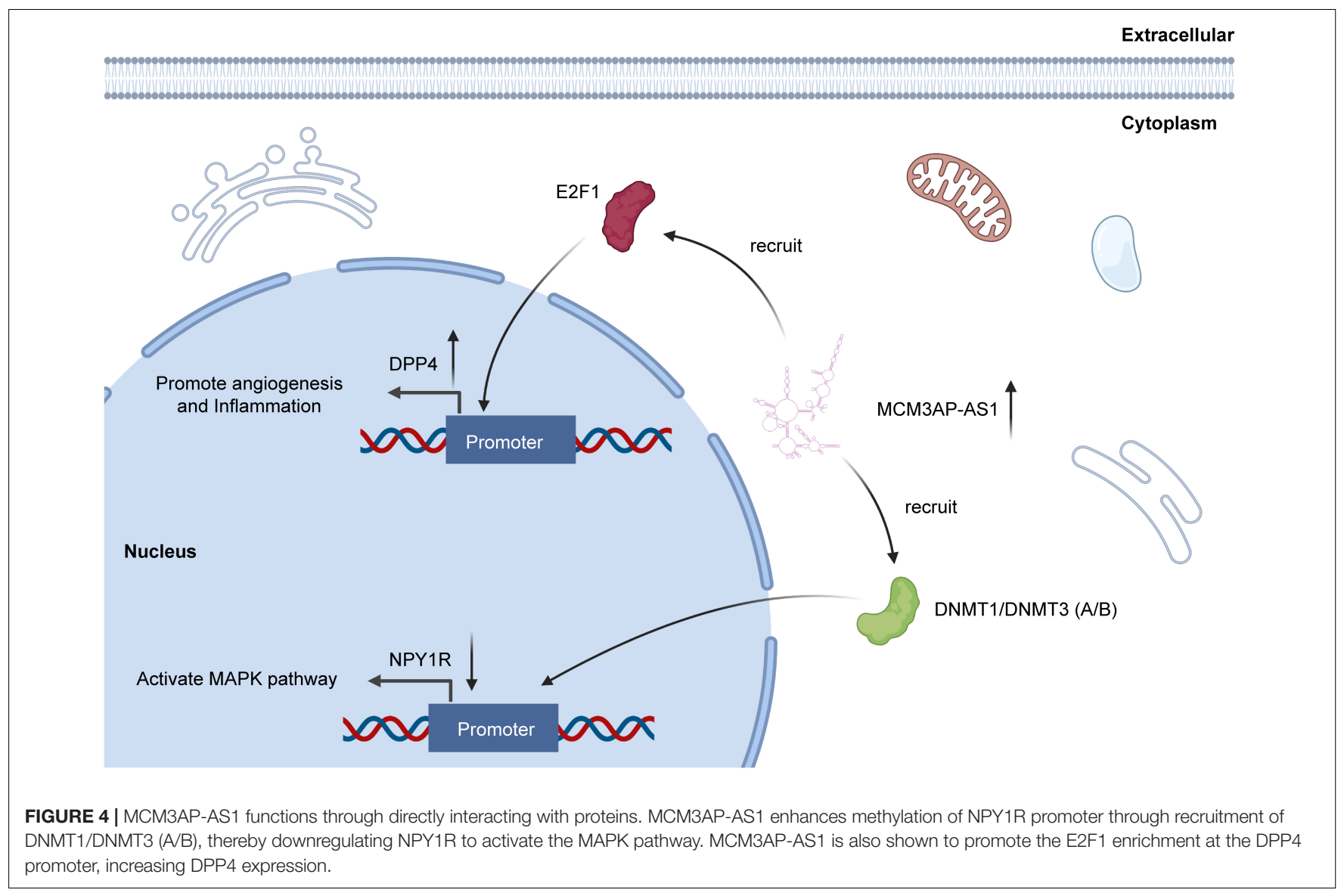

associated with OS of CRC patients (Zhou et al., 2021). MCM3AP-AS1 levels are also negatively correlated with OS in PCa, papillary thyroid cancer, and nasopharyngeal carcinoma (Liang et al., 2019; Jia et al., 2020; Sun et al., 2020; Chen et al., 2021). In addition, receiver operating characteristic (ROC) analyses showed that the specificity and sensitivity values of MCM3AP-AS1 were 0.58 and 0.76 , respectively, in breast cancer patients (Riahi et al., 2021). Therefore, MCM3AP-AS1 can be regarded as a potential diagnosis and prognosis biomarker in multiple cancers.

Treatment of cancer using molecular-targeted therapy is a promising strategy. MCM3AP-AS1 is a novel molecular target for cancer therapy. MCM3AP-AS1 regulates cancer progression through a series of pathways, such as miR-194-5p/FOXA1 (Wang et al., 2019e), miR-138-5p/FOXK1 (Yang et al., 2019), miR-2115p/SPARC (Liang et al., 2019), and miR-15a/EIF4E (Guo et al., 2020). And the miR-194-5p/FOXA1 axis is further confirmed in vivo experiments through constructing HCC xenograft model. MCM3AP-AS1 knockdown inhibits cell proliferation and colony formation in CRC (Yu Y. et al., 2021). Knockdown of MCM3AP-AS1 suppresses cell proliferation, migration, and invasion and promotes apoptosis in PCa cells and decreases the volume of $\mathrm{PCa}$ in $\mathrm{BALB} / \mathrm{c}$ mice (Jia et al., 2020; $\mathrm{Li}$ et al., 2020a; Wu et al., 2020). MCM3AP-AS1 knockdown increases gastric cancer cell sensitivity to cisplatin (Sun et al., 2021). Silencing miR-708-5p attenuates the inhibition of cell proliferation caused by MCM3AP-AS1 in gastric cancer (Wang et al., 2020). The upregulation of NPY1R inhibits the function of MCM3AP-AS1 by inactivating the MAPK pathway in PCa (Li et al., 2020a).

\section{CONCLUSION AND FUTURE PERSPECTIVES}

MCM3AP-AS1 is aberrantly expressed in human cancers, such as breast cancer, CRC, gastric cancer, HCC, and PCa. Its expression is significantly associated with several clinical characteristics. The levels of MCM3AP-AS1 are significantly associated with tumor size, TNM stage, pathological grade, and prognosis in different cancers. Additionally, it markedly promotes or suppresses tumor progression by controlling the biological functions of cells. For example, MCM3AP-AS1 upregulation promotes cell proliferation, colony formation, migration, and invasion and arrests the cell cycle at the G1 phase in CRC. MCM3AP-AS1 also plays an important role by interacting with specific molecules through a ceRNA mechanism. MCM3AP-AS1 facilitates proliferation by regulating the miR193a-5p/SENP1, miR-543-3p/SLC39A10/PTEN, and miR-8765p/WNT5A pathways.

Beyond participating in ceRNA network, lncRNA can also interact with protein directly (Ferre et al., 2016). And RNA 
binding protein immunoprecipitation (RIP) and RNA pulldown technology could verify the interactions between lncRNAs and protein (Bierhoff, 2018). As for MCM3AP-AS1, recent researches have revealed that MCM3AP-AS1 can directly interact with special proteins and further effect the biological functions of several cancers. Qiu et al. demonstrated that MCM3APAS1 could interact with E2F1 and enhance the enrichment of E2F1 at the DPP4 promoter, increasing the expression of DPP4. As a result, MCM3AP-AS1 promoted angiogenesis and inflammation in clear cell renal cell carcinoma (Qiu et al., 2020). Another study also revealed that MCM3APAS1 can recruit DNMT1/DNMT3 (A/B) to induce methylation of NPY1R promoter. In this way, MCM3AP-AS1 decreased NYP1R expression (Li et al., 2020a) (Figure 4). The interaction between lncRNA and protein is recently proposed molecular mechanism of lncRNA. However, for MCM3AP-AS1, researches related with this mechanism are still limited. Therefore, to explore the interaction between MCM3AP-AS1 and protein is an indispensable idea for future researchers.

Exosome is a kind of extracellular vesicles secreted by cells. Exosome exerts biological functions through transporting DNA, RNA, protein, and liquid among cells (Zhang Y. et al., 2020). And these components of exosomes could play a role in receptor cells to accomplish intercellular communication (Sun et al., 2018). Recent studies revealed that lncRNA could act as component of exosome and participate in the initiation and progression of cancers. Lang et al. demonstrated that gliomas could secrete exosomes containing lncRNA POU3F3 to promote the angiogenesis (Lang et al., 2017). Similar phenomenon was observed in breast cancer. LncRNA metastasis-associated lung adenocarcinoma transcript 1 (MALAT1) was upregulated in BC, and MALAT1 was transported by exosomes to accelerate BC cell proliferation (Zhang et al., 2018). More importantly, as long as released from cells, exosomes could enter circulatory system and be isolated from available body fluid for detection (Dong et al., 2019). Thus, it is probably a crucial research direction to further explore the roles of exosome lncRNA in human tumors.

\section{REFERENCES}

Almangush, A., Makitie, A. A., Triantafyllou, A., De Bree, R., Strojan, P., Rinaldo, A., et al. (2020). Staging and grading of oral squamous cell carcinoma: an update. Oral Oncol. 107:104799. doi: 10.1016/j.oraloncology.2020.104799

Amarasekera, C., Wong, V., Yura, E., Manjunath, A., Schaeffer, E., and Kundu, S. (2019). Prostate cancer in sexual minorities and the influence of HIV status. Nat. Rev. Urol. 16, 404-421. doi: 10.1038/s41585-019-0194-2

Andrei, L., Kasas, S., Ochoa Garrido, I., Stankovic, T., Suarez Korsnes, M., Vaclavikova, R., et al. (2020). Advanced technological tools to study multidrug resistance in cancer. Drug Resist. Updat. 48:100658. doi: 10.1016/j.drup.2019. 100658

Bade, B. C., and Dela Cruz, C. S. (2020). Lung cancer 2020: epidemiology, Etiology, and Prevention. Clin. Chest Med. 41, 1-24. doi: 10.1016/j.ccm.2019.10.001

Berger, A., Brady, N. J., Bareja, R., Robinson, B., Conteduca, V., Augello, M. A., et al. (2019). N-Myc-mediated epigenetic reprogramming drives lineage plasticity in advanced prostate cancer. J. Clin. Invest. 129, 3924-3940. doi: 10.1172/ JCI127961

Bierhoff, H. (2018). Analysis of lncRNA-protein interactions by RNA-protein pulldown assays and RNA immunoprecipitation (RIP). Methods Mol. Biol. 1686, 1241-1250. doi: 10.1007/978-1-4939-7371-2_17
Moreover, MCM3AP-AS1 is a promising biomarker for cancer diagnosis, prognosis evaluation, and treatment. However, there is a need for additional basic and clinical experimental results before these findings can be applied in the clinic. The process of drug development is difficult and challenging. At present, RNA drugs for some diseases have been successfully listed (Crooke et al., 2018). The types of RNA drugs considered feasible include oligonucleotides, mRNA, and RNA related small molecules. Considering the drug targeting and toxicity, oligonucleotide is a promising strategy and avenue for implementing gene therapy. The advantages of oligonucleotide lie in the convenience and efficient design. Delivering oligonucleotides directly in saline solution may maintain toxicity at a low level. Chemical modifications are also feasible methods to control toxicity and reduce off-target effects. Thus, oligonucleotides are a potential strategy for drug research and development (Roberts et al., 2020). Further drug research and development can refer to our point of view.

\section{AUTHOR CONTRIBUTIONS}

WG, YH, and SZ designed the review. XY, QZe, and QZa wrote this manuscript. XY searched the articles and made figures. All authors worked collaboratively on the work presented here, read, and approved the final manuscript.

\section{FUNDING}

This work was supported by the Leading Talents of Zhongyuan Science and Technology Innovation (214200510027), the Henan Provincial Medical Science and Technology Research Plan (SBGJ2018002), the Science and Technology Innovation Talents in Henan Universities (19HASTIT003), and the Outstanding Foreign Scientist Studio in Henan Province (GZS2020004).

Bray, F., Ferlay, J., Soerjomataram, I., Siegel, R. L., Torre, L. A., and Jemal, A. (2018). Global cancer statistics 2018: GLOBOCAN estimates of incidence and mortality worldwide for 36 cancers in 185 countries. CA Cancer J. Clin. 68, 394-424. doi: 10.3322/caac.21492

Carreira, H., Williams, R., Funston, G., Stanway, S., and Bhaskaran, K. (2021). Associations between breast cancer survivorship and adverse mental health outcomes: a matched population-based cohort study in the United Kingdom. PLoS Med. 18:e1003504. doi: 10.1371/journal.pmed.10 03504

Cebulla, J., Kim, E., Rhie, K., Zhang, J., and Pathak, A. P. (2014). Multiscale and multi-modality visualization of angiogenesis in a human breast cancer model. Angiogenesis 17, 695-709. doi: 10.1007/s10456-014-9429-2

Chen, Q., Xu, H., Zhu, J., Feng, K., and Hu, C. (2020). LncRNA MCM3AP-AS1 promotes breast cancer progression via modulating miR-28-5p/CENPF axis. Biomed. Pharmacother. 128:110289. doi: 10.1016/j.biopha.2020.1 10289

Chen, Y., Chen, Z., Mo, J., Pang, M., Chen, Z., Feng, F., et al. (2021). Identification of HCG18 and MCM3AP-AS1 that associate with bone metastasis, poor prognosis and increased abundance of M2 macrophage infiltration in prostate cancer. Technol. Cancer Res. Treat. 20:1533033821990064. doi: 10.1177/ 1533033821990064 
Costa, A. F., Campos, D., Reis, C. A., and Gomes, C. (2020). Targeting glycosylation: a new road for cancer drug discovery. Trends Cancer 6, 757-766. doi: 10.1016/j.trecan.2020.04.002

Crooke, S. T., Witztum, J. L., Bennett, C. F., and Baker, B. F. (2018). RNA-targeted therapeutics. Cell Metab. 27, 714-739. doi: 10.1016/j.cmet.2018.03.004

Cummins, T. D., Wu, K. Z. L., Bozatzi, P., Dingwell, K. S., Macartney, T. J., Wood, N. T., et al. (2018). PAWS1 controls cytoskeletal dynamics and cell migration through association with the SH3 adaptor CD2AP. J. Cell Sci. 131:jcs202390. doi: $10.1242 /$ jcs. 202390

Dai, W., Zeng, W., and Lee, D. (2021). IncRNA MCM3AP-AS1 inhibits the progression of colorectal cancer via the miR-19a-3p/FOXF2 axis. J. Gene Med. 23:e3306. doi: 10.1002/jgm.3306

Degasperi, E., Galmozzi, E., Pelusi, S., D’Ambrosio, R., Soffredini, R., Borghi, M., et al. (2020). Hepatic fat-genetic risk score predicts hepatocellular carcinoma in patients with cirrhotic HCV treated with DAAs. Hepatology 72, 1912-1923. doi: 10.1002/hep.31500

Dong, P., Xiong, Y., Yue, J., Hanley, S. J. B., Kobayashi, N., Todo, Y., et al. (2019). Exploring lncRNA-mediated regulatory networks in endometrial cancer cells and the tumor microenvironment: advances and challenges. Cancers 11:234. doi: $10.3390 /$ cancers 11020234

Ethier, J. L., Desautels, D., Robinson, A., Amir, E., Kong, W., and Booth, C. M. (2021). Practice patterns and outcomes of novel targeted agents for the treatment of ERBB2-positive metastatic breast cancer. JAMA Oncol. 7:e212140. doi: 10.1001/jamaoncol.2021.2140

Ferre, F., Colantoni, A., and Helmer-Citterich, M. (2016). Revealing proteinlncRNA interaction. Brief. Bioinform. 17, 106-116. doi: 10.1093/bib/bbv031

Gao, Q., Li, X. X., Xu, Y. M., Zhang, J. Z., Rong, S. D., Qin, Y. Q., et al. (2020). IRE1alpha-targeting downregulates ABC transporters and overcomes drug resistance of colon cancer cells. Cancer Lett. 476, 67-74. doi: 10.1016/j. canlet.2020.02.007

Ge, R., Wang, Z., Montironi, R., Jiang, Z., Cheng, M., Santoni, M., et al. (2020). Epigenetic modulations and lineage plasticity in advanced prostate cancer. Ann. Oncol. 31, 470-479. doi: 10.1016/j.annonc.2020.02.002

Germann, N., Gross-Goupil, M., Wasserman, E., Emile, J. F., Misset, J. L., Reynes, M., et al. (2002). The chemotherapy of metastatic gastric adenocarcinomas with hypersecretion of alpha-fetoprotein or beta-human chorionic gonadotrophin: report of two cases. Ann. Oncol. 13, 632-636. doi: 10.1093/annonc/mdf026

Goh, M. J., Sinn, D. H., Kim, S., Woo, S. Y., Cho, H., Kang, W., et al. (2020). Statin use and the risk of hepatocellular carcinoma in patients with chronic hepatitis B. Hepatology 71, 2023-2032. doi: 10.1002/hep.30973

Guo, C., Gong, M., and Li, Z. (2020). Knockdown of lncRNA MCM3AP-AS1 attenuates chemoresistance of Burkitt lymphoma to doxorubicin treatment via targeting the miR-15a/EIF4E axis. Cancer Manag. Res. 12, 5845-5855. doi: 10.2147/CMAR.S248698

Han, B., Sha, L., Yu, X., Yang, M., Cao, Y., and Zhao, J. (2021). Identification of dual therapeutic targets assisted by in situ automatous DNA assembly for combined therapy in breast cancer. Biosens. Bioelectron. 176:112913. doi: 10.1016/j.bios. 2020.112913

Harada, H., Soeno, T., Nishizawa, N., Washio, M., Sakuraya, M., Ushiku, H., et al. (2021). Prospective study to validate the clinical utility of DNA diagnosis of peritoneal fluid cytology test in gastric cancer. Cancer Sci. 112, 1644-1654. doi: $10.1111 /$ cas. 14850

Hernandez-Silva, C. D., Villegas-Pineda, J. C., and Pereira-Suarez, A. L. (2020). Expression and role of the G protein-coupled estrogen receptor (GPR30/GPER) in the development and immune response in female reproductive cancers. Front. Endocrinol. 11:544. doi: 10.3389/fendo.2020.00544

Hou, C., Wang, X., and Du, B. (2020). IncRNA MCM3AP-AS1 promotes the development of oral squamous cell carcinoma by inhibiting miR-363-5p. Exp. Ther. Med. 20, 978-984. doi: 10.3892/etm.2020.8738

Huang, X., Li, Z., Zhang, Q., Wang, W., Li, B., Wang, L., et al. (2019). Circular RNA AKT3 upregulates PIK3R1 to enhance cisplatin resistance in gastric cancer via miR-198 suppression. Mol. Cancer 18:71. doi: 10.1186/s12943-019-0969-3

Ivanova, T., Zouridis, H., Wu, Y., Cheng, L. L., Tan, I. B., Gopalakrishnan, V., et al. (2013). Integrated epigenomics identifies BMP4 as a modulator of cisplatin sensitivity in gastric cancer. Gut 62, 22-33. doi: 10.1136/gutjnl-2011-301113

Jena, B. C., and Mandal, M. (2021). The emerging roles of exosomes in anti-cancer drug resistance and tumor progression: an insight towards tumor-microenvironment interaction. Biochim. Biophys. Acta Rev. Cancer 1875:188488. doi: 10.1016/j.bbcan.2020.188488

Jia, Z., Li, W., Bian, P., Liu, H., Pan, D., and Dou, Z. (2020). LncRNA MCM3APAS1 promotes cell proliferation and invasion through regulating miR-5433p/SLC39A10/PTEN axis in prostate cancer. Onco Targets Ther. 13, 9365-9376. doi: 10.2147/OTT.S245537

Jin, J., Lu, P., Xu, Y., Li, Z., Yu, S., Liu, J., et al. (2021). PLncDB V2.0: a comprehensive encyclopedia of plant long noncoding RNAs. Nucleic Acids Res. 49, D1489-D1495. doi: 10.1093/nar/gkaa910

Jones, G. S., and Baldwin, D. R. (2018). Recent advances in the management of lung cancer. Clin. Med. 18, S41-S46. doi: 10.7861/clinmedicine.18-2-s41

Kang, H. G., Kim, W. J., Noh, M. G., Chun, K. H., and Kim, S. J. (2020). SPON2 is upregulated through notch signaling pathway and promotes tumor progression in gastric cancer. Cancers 12:1439. doi: 10.3390/cancers12061439

Kennedy, S. R., Zhang, Y., and Risques, R. A. (2019). Cancer-associated mutations but no cancer: insights into the early steps of carcinogenesis and implications for early cancer detection. Trends Cancer 5, 531-540. doi: 10.1016/j.trecan.2019. 07.007

Lan, L., Liang, Z., Zhao, Y., and Mo, Y. (2020). LncRNA MCM3AP-AS1 inhibits cell proliferation in cervical squamous cell carcinoma by down-regulating miRNA-93. Biosci. Rep. 40:BSR20193794. doi: 10.1042/BSR20193794

Lang, H.-L., Hu, G.-W., Chen, Y., Liu, Y., Tu, W., Lu, Y.-M., et al. (2017). Glioma cells promote angiogenesis through the release of exosomes containing long non-coding RNA POU3F3. Eur. Rev. Med. Pharmacol. Sci. 21, 959-972.

Li, H., Guo, J., Cheng, G., Wei, Y., Liu, S., Qi, Y., et al. (2021). Identification and validation of SNP-containing genes with prognostic value in gastric cancer via integrated bioinformatics analysis. Front. Oncol. 11:564296. doi: 10.3389/fonc. 2021.564296

Li, H., and Jiang, J. (2020). LncRNA MCM3AP-AS1 promotes proliferation, migration and invasion of oral squamous cell carcinoma cells via regulating miR-204-5p/FOXC1. J. Investig. Med. 68, 1282-1288. doi: 10.1136/jim-2020001415

Li, S., Xu, H. X., Wu, C. T., Wang, W. Q., Jin, W., Gao, H. L., et al. (2019). Angiogenesis in pancreatic cancer: current research status and clinical implications. Angiogenesis 22, 15-36. doi: 10.1007/s10456-0189645-2

Li, X., Lv, J., and Liu, S. (2020a). MCM3AP-AS1 KD inhibits proliferation, invasion, and migration of PCa cells via DNMT1/DNMT3 (A/B) methylation-mediated upregulation of NPY1R. Mol. Ther. Nucleic Acids 20, 265-278. doi: 10.1016/j. omtn.2020.01.016

Li, X., Yu, M., and Yang, C. (2020b). YY1-mediated overexpression of long noncoding RNA MCM3AP-AS1 accelerates angiogenesis and progression in lung cancer by targeting miR-340-5p/KPNA4 axis. J. Cell. Biochem. 121, 22582267. doi: $10.1002 /$ jcb. 29448

Liang, K., Liu, Q., and Kong, Q. (2021). New technologies in developing recombinant-attenuated bacteria for cancer therapy. Biotechnol. Bioeng. 118, 513-530. doi: 10.1002/bit.27596

Liang, M., Jia, J., Chen, L., Wei, B., Guan, Q., Ding, Z., et al. (2019). LncRNA MCM3AP-AS1 promotes proliferation and invasion through regulating miR211-5p/SPARC axis in papillary thyroid cancer. Endocrine 65, 318-326. doi: 10.1007/s12020-019-01939-4

Liang, Y., Zhang, H., Song, X., and Yang, Q. (2020). Metastatic heterogeneity of breast cancer: molecular mechanism and potential therapeutic targets. Semin. Cancer Biol. 60, 14-27. doi: 10.1016/j.semcancer.2019.08.012

Liu, S. J., Horlbeck, M. A., Cho, S. W., Birk, H. S., Malatesta, M., He, D., et al. (2017). CRISPRi-based genome-scale identification of functional long noncoding RNA loci in human cells. Science 355:aah7111. doi: 10.1126/science.aah7111

Liu, X., Yang, Z., Latchoumanin, O., and Qiao, L. (2016). Antagonizing programmed death-1 and programmed death ligand-1 as a therapeutic approach for gastric cancer. Ther. Adv. Gastroenterol. 9, 853-860. doi: 10.1177/ $1756283 \times 16658251$

Lorenzen, J. M., and Thum, T. (2016). Long noncoding RNAs in kidney and cardiovascular diseases. Nat. Rev. Nephrol. 12, 360-373. doi: 10.1038/nrneph. 2016.51

Luo, H., Zhang, Y., Qin, G., Jiang, B., and Miao, L. (2021). LncRNA MCM3AP-AS1 sponges miR-148a to enhance cell invasion and migration in small cell lung cancer. BMC Cancer 21:820. doi: 10.1186/s12885-021-08365-8 
Ma, X., Luo, J., Zhang, Y., Sun, D., and Lin, Y. (2020). LncRNA MCM3AP-AS1 upregulates CDK4 by sponging miR-545 to suppress G1 arrest in colorectal cancer. Cancer Manag. Res. 12, 8117-8124. doi: 10.2147/CMAR.S247330

Mao, G., Liu, Y., Fang, X., Liu, Y., Fang, L., Lin, L., et al. (2015). Tumorderived microRNA-494 promotes angiogenesis in non-small cell lung cancer. Angiogenesis 18, 373-382. doi: 10.1007/s10456-015-9474-5

Ng, J. H., Iyer, N. G., Tan, M. H., and Edgren, G. (2017). Changing epidemiology of oral squamous cell carcinoma of the tongue: a global study. Head Neck 39, 297-304. doi: 10.1002/hed.24589

Oki, E., Murata, A., Yoshida, K., Maeda, K., Ikejiri, K., Munemoto, Y., et al. (2016). A randomized phase III trial comparing S-1 versus UFT as adjuvant chemotherapy for stage II/III rectal cancer (JFMC35-C1: ACTS-RC). Ann. Oncol. 27, 1266-1272. doi: 10.1093/annonc/mdw162

Qiu, L., Ma, Y., Yang, Y., Ren, X., Wang, D., and Jia, X. (2020). Proangiogenic and pro-inflammatory regulation by lncRNA MCM3AP-AS1mediated upregulation of DPP4 in clear cell renal cell carcinoma. Front. Oncol. 10:705. doi: 10.3389/fonc.2020.00705

Ramjiawan, R. R., Griffioen, A. W., and Duda, D. G. (2017). Anti-angiogenesis for cancer revisited: is there a role for combinations with immunotherapy? Angiogenesis 20, 185-204. doi: 10.1007/s10456-017-9552-y

Riahi, A., Hosseinpour-Feizi, M., Rajabi, A., Akbarzadeh, M., Montazeri, V., and Safaralizadeh, R. (2021). Overexpression of long non-coding RNA MCM3APAS1 in breast cancer tissues compared to adjacent non-tumour tissues. $\mathrm{Br}$. J. Biomed. Sci. 78, 53-57. doi: 10.1080/09674845.2020.1798058

Roberts, T. C., Langer, R., and Wood, M. J. A. (2020). Advances in oligonucleotide drug delivery. Nat. Rev. Drug Discov. 19, 673-694. doi: 10.1038/s41573-0200075-7

Schwartz, A. G., and Cote, M. L. (2016). Epidemiology of lung cancer. Adv. Exp. Med. Biol. 893, 21-41. doi: 10.1007/978-3-319-24223-1_2

Seidlitz, T., Merker, S. R., Rothe, A., Zakrzewski, F., Von Neubeck, C., Grutzmann, K., et al. (2019). Human gastric cancer modelling using organoids. Gut 68, 207-217. doi: 10.1136/gutjnl-2017-314549

Shen, D., Li, J., Tao, K., and Jiang, Y. (2021). Long non-coding RNA MCM3AP antisense RNA 1 promotes non-small cell lung cancer progression through targeting microRNA-195-5p. Bioengineered 12, 3525-3538. doi: 10.1080/ 21655979.2021.1950282

Si, W., Shen, J., Zheng, H., and Fan, W. (2019). The role and mechanisms of action of microRNAs in cancer drug resistance. Clin. Epigenetics 11:25. doi: 10.1186/s13148-018-0587-8

Sun, H., Wu, P., Zhang, B., Wu, X., and Chen, W. (2021). MCM3AP-AS1 promotes cisplatin resistance in gastric cancer cells via the miR-138/FOXC1 axis. Oncol. Lett. 21:211. doi: 10.3892/ol.2021.12472

Sun, P., Feng, Y., Guo, H., Li, R., Yu, P., Zhou, X., et al. (2020). MiR-34a inhibits cell proliferation and induces apoptosis in human nasopharyngeal carcinoma by targeting lncRNA MCM3AP-AS1. Cancer Manag. Res. 12, 4799-4806. doi: 10.2147/CMAR.S245520

Sun, Z., Yang, S., Zhou, Q., Wang, G., Song, J., Li, Z., et al. (2018). Emerging role of exosome-derived long non-coding RNAs in tumor microenvironment. Mol. Cancer 17:82. doi: 10.1186/s12943-018-0831-z

Swaminathan, V., Fischer, R. S., and Waterman, C. M. (2016). The FAK-Arp2/3 interaction promotes leading edge advance and haptosensing by coupling nascent adhesions to lamellipodia actin. Mol. Biol. Cell 27, 1085-1100. doi: 10.1091/mbc.E15-08-0590

Thum, T. (2014). Noncoding RNAs and myocardial fibrosis. Nat. Rev. Cardiol. 11, 655-663. doi: 10.1038/nrcardio.2014.125

Tojkander, S., Gateva, G., Husain, A., Krishnan, R., and Lappalainen, P. (2015). Generation of contractile actomyosin bundles depends on mechanosensitive actin filament assembly and disassembly. Elife 4:e06126. doi: 10.7554/eLife. 06126

Torre, L. A., Islami, F., Siegel, R. L., Ward, E. M., and Jemal, A. (2017). Global cancer in women: burden and trends. Cancer Epidemiol. Biomarkers Prev. 26, 444-457. doi: 10.1158/1055-9965.EPI-16-0858

Wang, G., Zhang, Z. J., Jian, W. G., Liu, P. H., Xue, W., Wang, T. D., et al. (2019a). Novel long noncoding RNA OTUD6B-AS1 indicates poor prognosis and inhibits clear cell renal cell carcinoma proliferation via the Wnt/betacatenin signaling pathway. Mol. Cancer 18:15. doi: 10.1186/s12943-0190942-1
Wang, J., Xie, S., Yang, J., Xiong, H., Jia, Y., Zhou, Y., et al. (2019b). The long noncoding RNA H19 promotes tamoxifen resistance in breast cancer via autophagy. J. Hematol. Oncol. 12:81. doi: 10.1186/s13045-019-0747-0

Wang, J., Zhou, J., Jiang, C., Zheng, J., Namba, H., Chi, P., et al. (2019c). LNRRIL6, a novel long noncoding RNA, protects colorectal cancer cells by activating the IL-6-STAT3 pathway. Mol. Oncol. 13, 2344-2360. doi: 10.1002/1878-0261. 12538

Wang, Y. G., Wang, T., Shi, M., and Zhai, B. (2019f). Long noncoding RNA EPB41L4A-AS2 inhibits hepatocellular carcinoma development by sponging miR-301a-5p and targeting FOXL1. J. Exp. Clin. Cancer Res. 38:153. doi: 10. 1186/s13046-019-1128-9

Wang, W., Kandimalla, R., Huang, H., Zhu, L., Li, Y., Gao, F., et al. (2019d). Molecular subtyping of colorectal cancer: recent progress, new challenges and emerging opportunities. Semin. Cancer Biol. 55, 37-52. doi: 10.1016/j. semcancer.2018.05.002

Wang, Y., Yang, L., Chen, T., Liu, X., Guo, Y., Zhu, Q., et al. (2019e). A novel lncRNA MCM3AP-AS1 promotes the growth of hepatocellular carcinoma by targeting miR-194-5p/FOXA1 axis. Mol. Cancer 18:28. doi: 10.1186/s12943019-0957-7

Wang, H., Xu, T., Wu, L., Xu, H. L., and Liu, R. M. (2020). Molecular mechanisms of MCM3AP-AS1 targeted the regulation of miR-708-5p on cell proliferation and apoptosis in gastric cancer cells. Eur. Rev. Med. Pharmacol. Sci. 24, 24522461. doi: 10.26355/eurrev_202003_20512

Wang, X., Zhang, H., Bai, M., Ning, T., Ge, S., Deng, T., et al. (2018). Exosomes serve as nanoparticles to deliver anti-miR-214 to reverse chemoresistance to cisplatin in gastric cancer. Mol. Ther. 26, 774-783. doi: 10.1016/j.ymthe.2018. 01.001

Wu, J., Lv, Y., Li, Y., Jiang, Y., Wang, L., Zhang, X., et al. (2020). MCM3APAS1/miR-876-5p/WNT5A axis regulates the proliferation of prostate cancer cells. Cancer Cell Int. 20:307. doi: 10.1186/s12935-020-01365-x

Wu, Y. Y., Chen, Y. L., Jao, Y. C., Hsieh, I. S., Chang, K. C., and Hong, T. M. (2014). miR-320 regulates tumor angiogenesis driven by vascular endothelial cells in oral cancer by silencing neuropilin 1. Angiogenesis 17, 247-260. doi: 10.1007/s10456-013-9394-1

Xia, P., Zhang, H., Xu, K., Jiang, X., Gao, M., Wang, G., et al. (2021). MYCtargeted WDR4 promotes proliferation, metastasis, and sorafenib resistance by inducing CCNB1 translation in hepatocellular carcinoma. Cell Death Dis. 12:691. doi: 10.1038/s41419-021-03973-5

Xu, H., Brown, A. N., Waddell, N. J., Liu, X., Kaplan, G. J., Chitaman, J. M., et al. (2020). Role of long noncoding RNA Gas5 in cocaine action. Biol. Psychiatry 88, 758-766. doi: 10.1016/j.biopsych.2020.05.004

Yang, C., Zheng, J., Xue, Y., Yu, H., Liu, X., Ma, J., et al. (2017). The effect of MCM3AP-AS1/miR-211/KLF5/AGGF1 axis regulating glioblastoma angiogenesis. Front. Mol. Neurosci. 10:437. doi: 10.3389/fnmol.2017.00437

Yang, M., Sun, S., Guo, Y., Qin, J., and Liu, G. (2019). Long non-coding RNA MCM3AP-AS1 promotes growth and migration through modulating FOXK1 by sponging miR-138-5p in pancreatic cancer. Mol. Med. 25:55. doi: 10.1186/ s10020-019-0121-2

Yarla, N. S., Gali, H., Pathuri, G., Smriti, S., Farooqui, M., Panneerselvam, J., et al. (2019). Targeting the paracrine hormone-dependent guanylate cyclase/cGMP/phosphodiesterases signaling pathway for colorectal cancer prevention. Semin. Cancer Biol. 56, 168-174. doi: 10.1016/j.semcancer.2018.08. 011

Yip, T. C., Wong, V. W., Chan, H. L., Tse, Y. K., Lui, G. C., and Wong, G. L. (2020). Tenofovir is associated with lower risk of hepatocellular carcinoma than entecavir in patients with chronic HBV infection in China. Gastroenterology 158, 215-225.e6. doi: 10.1053/j.gastro.2019.09.025

Yu, J., Fan, Q., and Li, L. (2021). The MCM3AP-AS1/miR-126/VEGF axis regulates cancer cell invasion and migration in endometrioid carcinoma. World J. Surg. Oncol. 19:213. doi: 10.1186/s12957-021-02316-0

Yu, Y., Lai, S., and Peng, X. (2021). Long non-coding RNA MCM3APAS1 facilitates colorectal cancer progression by regulating the microRNA599/ARPP19 axis. Oncol. Lett. 21:225. doi: 10.3892/ol.2021.12486

Zehendner, C. M., Valasarajan, C., Werner, A., Boeckel, J. N., Bischoff, F. C., John, D., et al. (2020). Long noncoding RNA TYKRIL plays a role in pulmonary hypertension via the p53-mediated regulation of PDGFR $\beta$. Am. J. Respir. Crit. Care Med. 202, 1445-1457. doi: 10.1164/rccm.201910-2041OC 
Zhang, H., Luo, C., and Zhang, G. (2019). LncRNA MCM3AP-AS1 regulates epidermal growth factor receptor and autophagy to promote hepatocellular carcinoma metastasis by interacting with miR-455. DNA Cell Biol. 38, 857-864. doi: 10.1089/dna.2019.4770

Zhang, P., Zhou, H., Lu, K., Lu, Y., Wang, Y., and Feng, T. (2018). Exosomemediated delivery of MALAT1 induces cell proliferation in breast cancer. Onco Targets Ther. 11, 291-299. doi: 10.2147/OTT.S155134

Zhang, Q., Zhang, H., Ning, T., Liu, D., Deng, T., Liu, R., et al. (2020). Exosome-delivered c-Met siRNA could reverse chemoresistance to cisplatin in gastric cancer. Int. J. Nanomedicine 15, 2323-2335. doi: 10.2147/IJN.S2 31214

Zhang, Y., Bi, J., Huang, J., Tang, Y., Du, S., and Li, P. (2020). Exosome: a review of its classification, isolation techniques, storage, diagnostic and targeted therapy applications. Int. J. Nanomedicine 15, 6917-6934. doi: 10.2147/IJN.S2 64498

Zhao, H., Huang, C., Luo, Y., Yao, X., Hu, Y., Wang, M., et al. (2021). A correlation study of prognostic risk prediction for colorectal cancer based on autophagy signature genes. Front. Oncol. 11:595099. doi: 10.3389/fonc.2021.595099

Zhou, M., Bian, Z., Liu, B., Zhang, Y., Cao, Y., Cui, K., et al. (2021). Long noncoding RNA MCM3AP-AS1 enhances cell proliferation and metastasis in colorectal cancer by regulating miR-193a-5p/SENP1. Cancer Med. 10, 2470-2481. doi: $10.1002 /$ cam 4.3830
Zhou, T., Liang, X., Wang, P., Hu, Y., Qi, Y., Jin, Y., et al. (2020). A hepatocellular carcinoma targeting nanostrategy with hypoxia-ameliorating and photothermal abilities that, combined with immunotherapy, inhibits metastasis and recurrence. ACS Nano 14, 12679-12696. doi: 10.1021/acsnano. $0 \mathrm{c} 01453$

Conflict of Interest: The authors declare that the research was conducted in the absence of any commercial or financial relationships that could be construed as a potential conflict of interest.

Publisher's Note: All claims expressed in this article are solely those of the authors and do not necessarily represent those of their affiliated organizations, or those of the publisher, the editors and the reviewers. Any product that may be evaluated in this article, or claim that may be made by its manufacturer, is not guaranteed or endorsed by the publisher.

Copyright (C) 2021 Yu, Zheng, Zhang, Zhang, He and Guo. This is an open-access article distributed under the terms of the Creative Commons Attribution License (CC BY). The use, distribution or reproduction in other forums is permitted, provided the original author(s) and the copyright owner(s) are credited and that the original publication in this journal is cited, in accordance with accepted academic practice. No use, distribution or reproduction is permitted which does not comply with these terms. 